Nippon Suisan Gakkaishi $\quad 59(3), 461-464(1993)$

\title{
Genetic Determination of the Growth of the Guppy
}

\author{
Masamichi Nakajima* and Yoshihisa Fujio* \\ (Received August 10, 1992)
}

\begin{abstract}
Comparative growth profiles were investigated for strain difference in 8 strains of the guppy Poecilia reticulata. There was an obvious difference in body length between female and male from Day 60, which became more pronounced with growth to Day 180. Differences in body length between strains were found significantly at each age.

Using strain comparison, the heritability of body length at various ages was estimated, and this heritability changed with age. The change of heritability suggests different genetic control in three stages for the growth curve. They are maternal genotypic effects on the body size at birth, growth genes in the growing stage, and an inhibitory gene influencing final body size.
\end{abstract}

It is known that the characteristics of fish growth, although in many ways resembling those of the growth of higher vertebrates, possess interesting genetic differences that should be made explicit. Whereas higher vertebrates have final body size with full sexual maturity, most fish reach first maturity in the attainment of a critical minimal size and then continue growing during their lifefimes.

The phenotypic variation for growth is caused, at least in part, by the action of many minor genes whcih individually have small effects. In reviwing the heritability of growth in weight at various ages in salmonids, Kinghorn ${ }^{12}$ has reported that there is a general tendency for heritability to increase with age. But the heritability of growth has not been estimated at various ages in the same population. It is important for fish breeding to elucidate the change in genetic control of growth at various ages in the same population.

Genetic differences between strains or populations within cultured fish species has been demonstrated in guppy, ${ }^{2)}$ Japanese char, ${ }^{3)}$ masu salmon, ${ }^{4)}$ rainbow trout, ${ }^{57}$ and carp $^{6,7)}$ from gene frequencies at individual loci detected by gel electrophoresis. Furthermore, differences in performance between strains or populations within cultured fish species have been documented. ${ }^{12}$ Since the resemblance between relatives indicates the proportion of genetic determination of the character, the strain differences indicate the genetic influence on the variation of performance. Chevassus ${ }^{8 /}$ estimated the coef- ficient of variation in mean fingerling weight between strains of rainbow trout to be $20 \%$. Refstie and Steine ${ }^{\theta)}$ reported genetic variation in length and weight after the freshwater phase in 32 Norweigian strains of Atlantic salmon. Wohlfarth et al. ${ }^{10)}$ reported differences in growth rate between strains of carp. Macaranas and Fujio ${ }^{11}$ reported size differences among strains of the guppy.

In the present work, using strain comparisons of the guppy, the heritability of body length at various ages was estimated and the change of genetic influence with age was discussed.

\section{Materials and Methods}

To make a simultaneous study of growth, the guppy Poecilia reticulata was used as a model fish. Eight guppy strains selected for body color pattern and body size have been maintained as closed colonies in $60 l$ aquaria at reasonable densities of 300-500 individuals per aquarium, depending on the average size of the strain. ${ }^{2)}$ Eight strains were genetically differentiated at the isozyme loci.

Guppy pairs of every strain were taken at random from the parent stocks and were reared in $2.5 l$ aquaria until the birth of the offspring. At least 7 pairs per strain were used to obtain the offspring. The offspring were reared at a maximum density of 8 individuals from each pair. Guppies were maintained at $23 \pm 2^{\circ} \mathrm{C}$ on a pelletized carp diet administrated twice daily, and dried Daphnia was given as a supplement. Stand-

* Faculty of Agriculture, Tohoku University, Tsutsumidori-amemiya, Aoba, Sendai, Miyagi 981, Japan (中唯正道, 藤尾芳久: 東北大学農学部). 
ard body lengths were measured at 15-day intervals from Day 0 to Day 180.

Heritability was estimated by standard analysisof-variance techniques. ${ }^{12}$ ) The expected mean square between strains is equal to $\sigma \mathrm{E}^{2}+\mathrm{k} \sigma \mathrm{G}^{2}$, where $\sigma \mathrm{E}^{2}$ and $\sigma \mathrm{G}^{2}$ are the environmental and genetic components of variance, respectively, and $\mathrm{k}$ is the number of individuals measured per strain (or the hearmonic mean of the numbers in the strain if the sample sizes are not equal). The expected mean square within strains is equal to $\sigma \mathrm{E}^{2}$.

\section{Results}

Growth curves of 8 guppy strains, S, S2, S3, $F, M, G, T$, and $T 1$, are shown in Fig. 1. Sex differentiation usually occurred between Day 45-60. There was an obvious difference in body length between females and males from Day 60, which became more pronounced with growth to Day 180. At Day 60, average female body length in each strain ranged between 14.6 and $18.3 \mathrm{~mm}$, while average male body length ranged between 13.7 and $17.6 \mathrm{~mm}$. At Day 180 , average female body length in each strain ranged between 24.0 and $29.7 \mathrm{~mm}$, while average male body length ranged between 16.0 and 20.6 $\mathrm{mm}$. This indicates that the growth rate of males is slower than that of females.

Significant differences between strains were found at each age. The S3 strain, which was an isolate of the $\mathrm{S}$ strain, displayed a significant difference in growth rate fom the $S$ strain. The $\mathrm{T} 1$ strain, which was an isolate of the $\mathrm{T}$ strain, also displayed a significant difference in growth rate from the $T$ strain. These results suggest that genetic variation for the growth rate exists within strains and that the genes fluctuate due to genetic drift.

To estimate the proportion of genetic determination for growth at each age, the heritability was calculated by standard analysis-of-variance techniques. The results are presented in Fig. 2. From a comparison between 8 strains for body length, the heritability was 0.424 at Day $0,0.063$ at Day $15,0.71$ at Day 30 and 0.227 at Day 45 . After sexual differentiation (Day 60), the profiles of heritability with age followed different patterns between females and males. With respect to female body length from Day 45 to Day 180 , the heritability ranged between 0.198 and 0.368

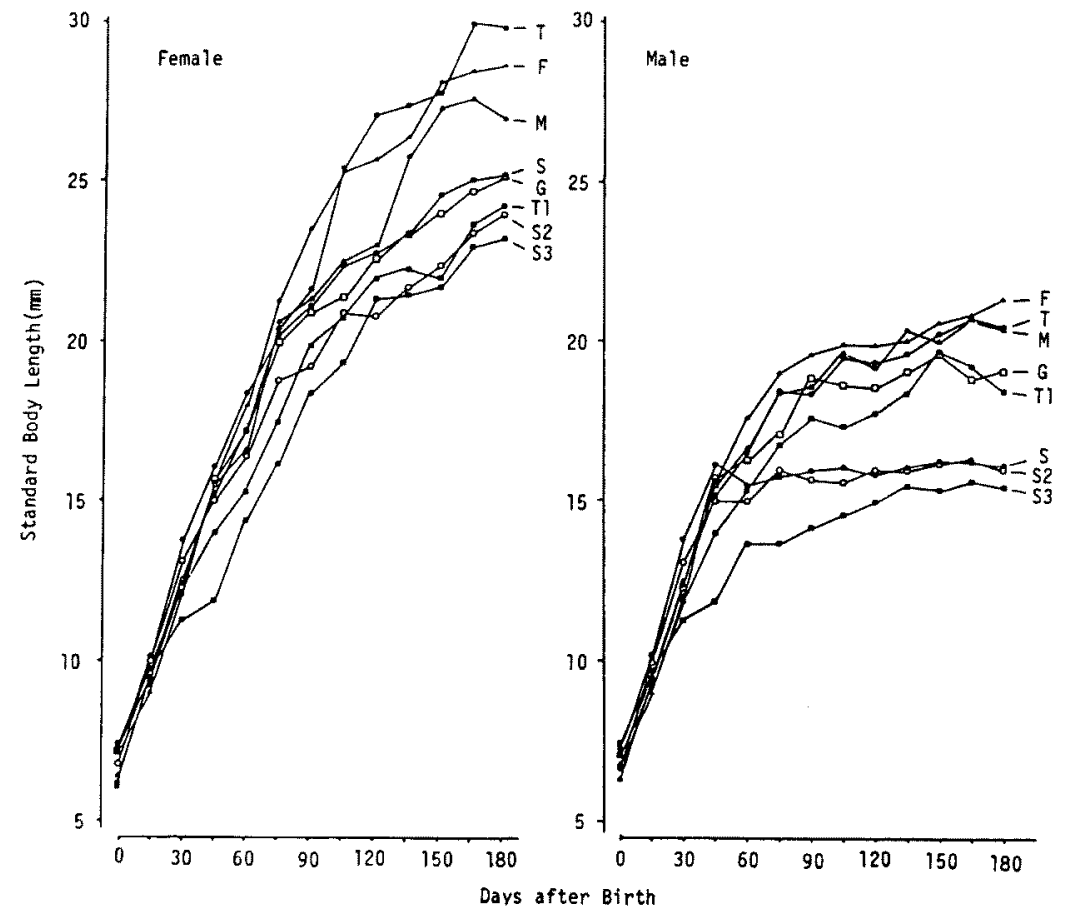

Fig. 1. Comparative growth profiles in females and males of 8 guppy strains. 


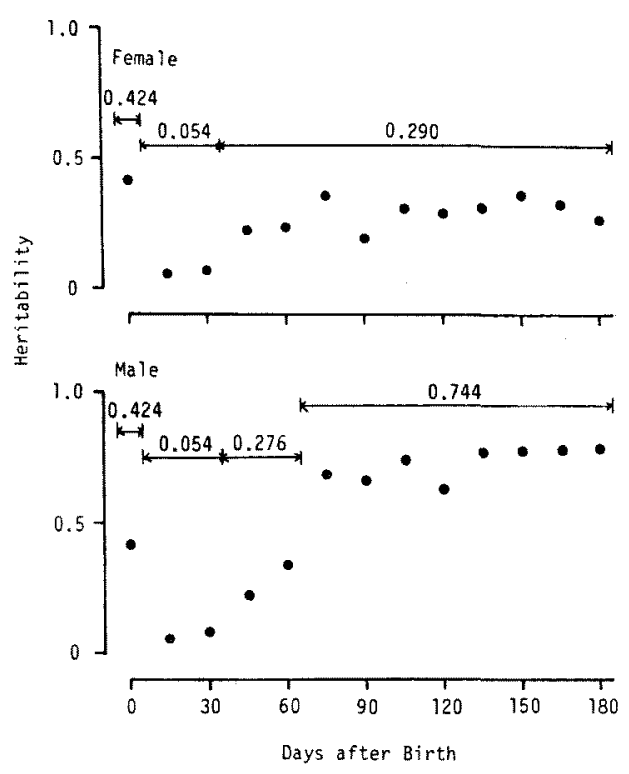

Fig. 2. Change in heritability estimated by strain comparison with age in the guppy.

with an average of 0.290 , indicating the stable level. On the other hand, the heritability from Day 60 to Day 180 in males ranged between 0.667 and 0.799 with an average of 0.744 , this stable level being higher than in females.

\section{Discussion}

Genotype-environmental interaction can be an important factor in analysis of quantative character such as growth. Moav et al. ${ }^{13)}$ found evidence that the environmental interaction was significantly large for the growth rate in carp. Klupp et al. ${ }^{14}$ reported a high genetic correlation of 0.67 between growth in ponds for 3 strains of rainbow tout. This must be interpreted with caution, as the assumption of no environmental differences between ponds could give rise to the apparent interaction involved.

Estimations of heritability are available from strain comparison. However, the values of such estimates depend on the following factors. (1)

The genetic models employed assumed a simple additive relationship between genetic and environmental effects. The epistatic and dominance effects are involved in the estimation. (2) Component of variance is biased due to the existence of genetic variance within a strain. (3) The effects of sampling errors are involved both in the

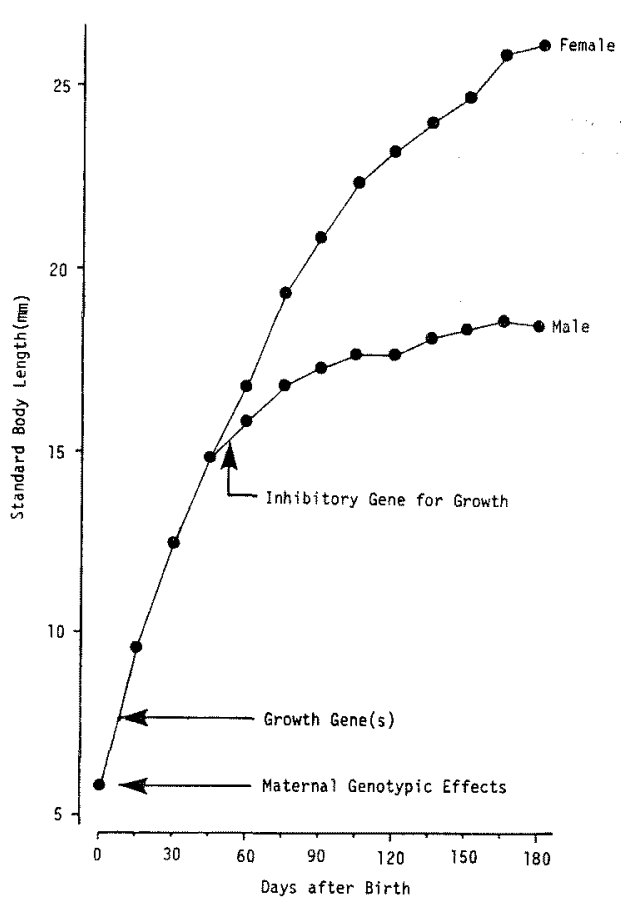

Fig. 3. Schematic genetic controls for the growth of the guppy.

parents and in the offspring.

Most sources of bias cause overestimation of heritability values. But in the same population, the relative values for heritability indicate the change of genetic influence with age.

The changes of heritability with age suggest three different genetic controls in three stages for the growth curve (Fig. 3). They are maternal genotypic effects on body size at birth, growth gene at the growing stage, and an inhibitory gene influencing final body size. Heritability at birth indicates maternal genotypic effects. When the offspring size which depends on the female body size is larger, the body size at birth is smaller. Low heritability $(0.054)$ obtained at Day 15 and 30 is interpreted by the offset between maternal genotypic effects and the expression of growth genes. The heritability $(0.290)$ obtained from Day 45 to Day 180 in females indicates the variation of growth genes due to the growth rate of the guppy. This prediction was supported by the estimation obtained from Day 45 and 60 in males. Kinghorn ${ }^{12}$ has reported in his review that the heritability of gowth appears to average approximately $20 \%$ in rainbow trout and $30 \%$ 
in Atlantic salmon. The present estimation is at a similar level to these. High heritability $(0.744)$ obtained from Day 60 to Day 180 in males suggests the existence of and inhibitoy gene due to the final body size of males.

\section{References}

1) B. P. Kinghorn: A review of quantitative genetics in fish breeding. Aquoculture, 31, 283-304 (1983).

2) J.M. Macaranas and Y. Fujio: Genetic differences among strains of the guppy, Poecilia reticulata. Tohoku J. Agr. Res., 37, 75-85 (1987).

3) J. M. Macaranas, M. Nakajima, and Y. Fujio: Genetic differentiation among cultured populations of Japanese char. Tohoku J. Agr. Res., 36. 117-125 (1985).

4) M. Nakajima, A. Kita, and Y. Fujio: Genetic features of natural and cultured populations of masu salmon. Tohoku J. Agr. Res., 37, 31-41 (1986).

5) M. Nakajima and Y. Fujio: Genetic differentiation in cultured populations of rainbow trout (Salmo grairdneri) in Japan. Tohoku J. Agr. Res., 38, 35-48 (1988).

6) T. Brody, D. Kirsht, G. Parag, G. Wohlfarth, G. Hulata, and R. Moav: Biochemical genetics comparison of the Chinese and European races of the common carp. Anim. Blood Groups Biochem. Genet., 10, 141-149 (1979).
7) Y. Kosaka, Y. Fujio, and R. Suzuki: Genetic characterization of some races of carp. Fish Genefics and Breeding Sci., 5, 22-26 (1980) (in Japanese).

8) B. Chevassus: Variabilite et heritabilite des performances de croissance chez la truite aer-en-ciel (Salmo gairdneri Richardson). Ann. Genet. Sel. Anim., 8, 273-283 (1976).

9) T. Refstic and T.A. Steine: Selection experiments with salmon. III. Genetic and environmental sources of variation in length and weight of Atlantic saimon in the freshwater phase. Aquaculture, 14, 221-234 (1978).

10) G. Wohlfarth, R. Moav, and G. Hulata: Genetic differences between the Chinese and European races of the common carp. II. Multicharacter variation-a response to the diverse methods of fish cultivation in Europe and China. Heredity, 34, 341-350 (1975).

11) J. M. Macaranas and Y. Fujio: Strain differences in cultured fish-Isozymes and performance traits as indicators. Aquaculture, 85, 69-82 (1990).

12) D.S. Falconer: Introduction to Quantitative Genetics, 2nd ed. Longman, London, 1981, p. 340.

13) R. Moav, $G$. Mulata, and $G$. Woblfarth: Genetic differences between the Chinese and European races of common carp. I. Analysis of genotype, environment interactions for growth rate. Heredity, 34, 323-340 (1975).

14) $R, H$ Klop, G. Heil, and $F$. Pirchner: Effects of interaction between strains and environments on growtb trait in rainbow trout (Salmo gairdneri). Aquaculture, 14, 271-295 (1978). 